\title{
LA SOCIEDAD ESPAÑOLA DE LA DÉCADA DE LOS SESENTA EN EL TEATRO DE ALFONSO PASO
}

\author{
Javier Sánchez Abarca
}

Dejando al margen cualquier consideración literaria con respecto a la extensa producción dramática de Alfonso Paso, tenemos que señalar que el gran interés de su obra reside en su innegable aspecto sociológico. A lo largo de las numerosas comedias que conforman su trayectoria teatral el dramaturgo madrileño «refleja el proceso sufrido por nuestra pequeña burguesía a lo largo de más de un cuarto de siglo» ${ }^{1}$. Como señala Julio Mathias, «nadie puede negar que Paso se ha ocupado y preocupado por los problemas actuales. No por los de una actualidad inglesa, francesa o norteamericana, sino por los problemas de la actualidad española que es lo más importante para su mentalidad de autor español $»^{2}$. Sin embargo, y a pesar de que el teatro de Paso «responde a los hechos concretos de la sociedad en la que se desarrolla y vive» ${ }^{3}$, nuestro dramaturgo selecciona cuidadosamente los temas sobre los que van a versar sus comedias, descartando y desechando aquellos que tienen un trasfondo polémico y crítico que pueden perjudicar el tono cómico y el final conciliador tan característico de sus obras.

Esta circunstancia hace que el dramaturgo madrileño se vea obligado a hacer una selección de tipos, evitando incluir en sus obras a personajes insertos en una realidad social marginal y optando por articular sus comedias mediante personajes pertenecientes a la clase popular y clase media. Éstos muestran una serie de pequeños problemas, generalmente de la vida cotidiana -relaciones matrimoniales, convivencia familiar, problemas laborales-, que van acrecentándose

1. Monlé́n, José, «Esplendor y decadencia de una tragicomedia», El País, 11 de julio de 1978, p. 17.

2. Mathias, Julio, Alfonso Paso, Madrid, Epesa, 1971, p. 66.

3. Ibidem, p. 106. 
poco a poco debido a su inmediatez. Sin embargo, estas dificultades no dejan de ser una mera excusa para reflejar de una manera ingenua, amable e incluso irónica, la realidad social del momento, de la que Paso resalta los aspectos más superficiales y triviales con los que no sólo pretende divertir a un público que le es mayoritariamente favorable, sino también consolidar las estructuras morales e ideológicas del régimen franquista.

Además de esto, todo lo que rodea a la obra y a sus personajes -habla, caracterización, localización, escenografía- tiene una base real y verosímil que, dada su contemporaneidad, el espectador reconoce rápida y fácilmente. De esta manera se produce, como señala Molero Manglano, «una identificación con la sociedad y el público de su tiempo» $»^{4}$, que es, sin ninguna duda, una de las claves sobre la que se cimenta el innegable éxito teatral de Alfonso Paso. Así pues, podemos afirmar que el teatro de nuestro dramaturgo está diseñado específicamente por y para la sociedad de su tiempo, y, lejos de ésta, las obras van perdiendo fuerza gradualmente y tienden a caer en el olvido. Esta circunstancia hace que para el lector/espectador actual muchas de las obras de Alfonso Paso resulten demasiado lejanas en el tiempo, demasiado ancladas en un ambiente y en una realidad social muy diferente a la actual, cada vez más justa, más igualitaria y con problemas sociales muy distintos a los de la España de los años sesenta.

Así pues, a partir de este momento nuestro estudio se centrará en analizar de qué manera se refleja la sociedad de la década de los sesenta en las comedias de Alfonso Paso. Para esto nos valdremos de algunas de las obras más representativas -siempre desde el punto de vista sociológico- del dramaturgo madrileño, como Veraneando, Las que tienen que servir, La corbata, ¡Estos chicos de ahora!, Prefiero España, La boda de la chica, Mamá con niña o Cuando tú me necesites.

\section{La clase media en las comedias de Alfonso Paso}

A lo largo de la ingente producción teatral de Alfonso Paso desfila una amplia galería de personajes pertenecientes a todas y cada una de las clases sociales de la España de su tiempo. Sin embargo, la mayoría de éstos pertenecen a lo que hemos denominado como clase media. Como señala Ilárraz Eslava, «dos son las vertientes más importantes por las que se desliza esta clase media: una, la vertiente de los que parecen irse hundiendo irremisiblemente en la pobreza del miserable, y, la otra, la de los que alejándose considerablemente del modesto vi-

4. Molero Manglano, Luis, Teatro español contemporáneo, Madrid, Editora Nacional, 1974, p. 119. 
vir del hombre van adentrándose en la frívola esfera del nuevo rico o del hombre de vivir acomodado» ${ }^{5}$.

En la vertiente más baja de esta clase media se encuentran, según palabras del propio Alfonso Paso, los que siguen «manteniendo en casa sus espantosos enfermos, negándose a llevar al manicomio a sus locos, atenazada por mil problemas sin solución y todavía portadora y guardadora celosa de las tradiciones de mi país ${ }^{6}$. Este grupo social aparece representado en las obras del madrileño por funcionarios medios -Medardo en Los pobrecitos-, pequeños oficinistas y comerciantes -Antonio en La corbata y Clotilde en Tan alegre, tan extraño-, artistas por consagrar -Carlos en Los pobrecitos-y, en general, todas aquellas personas con escasas rentas patrimoniales y con pensiones que sólo dan para subsistir. Un claro ejemplo de este último grupo lo encontramos en Mamá con niña. En esta divertida comedia, estrenada el 23 de diciembre de 1964 en el Teatro Infanta Isabel de Madrid, Paso refleja la historia de una madre solitaria y de una hija enfermiza que no puede casarse porque de hacerlo perdería la pensión con la que ambas sobreviven:

IRENE.- No ponga casos... Si mi hija se casa, la pensión se extingue; si mi hija profesa, la pensión se extingue; si mi hija se muere, la pensión se extingue. Total, que pongámonos como nos pongamos, por menos de un pito se extingue la pensión, y en cuanto se extinga la pensión me extingo yo. ${ }^{7}$

En contraposición a estos personajes, encontramos lo que podríamos denominar como clase media aburguesada, es decir, la vertiente más acomodada de este amplio grupo social. Como representantes de ésta podemos citar a médicos, ingenieros, directores de bancos y empresas, jefes de departamentos ministeriales y prósperos comerciantes. La diferencia más evidente e importante entre ambos grupos reside en su nivel económico y poder adquisitivo. La clase media popular, además de carecer de los adelantos y comodidades que proporciona la vida moderna, -vacaciones, coche, televisor, electrodomésticos, servicio doméstico y de cualquier otro elemento derivado del desarrollismo de la España de los sesenta- se ve obligada a hacer frente a los gastos primarios de la forma más variopinta. Los pobrecitos, una de las obras en las que aparece ampliamente reflejado este grupo social, nos ofrece un claro ejemplo de lo que decimos: don Pablo, coronel retirado, y Carlos, escritor de medio pelo, no dudan en empeñar

5. IlárRaz EsLava, Félix Guillermo, «La sufrida y alegre clase media en las comedias de Alfonso Paso», Separata de la Revista de Estudios Hispánicos, IV, 1, (1972), p. 121.

6. Paso, Alfonso, La corbata, Madrid, Escélicer, 1963, p. 5.

7. Paso, Alfonso, Mamá con niña, Madrid, Escélicer, 1965, p. 15. 
sus objetos personales más valiosos con el fin de obtener el dinero suficiente para poder pagar la pensión en la que viven:

Carlos.- Con algún dinero, por poco que fuese, le taparía la boca a ese pulpo. Voy a empeñar este reloj. [...]

Don Pablo.- Hombre, allí he empeñado yo el sable y un ros que me dieron seis duros, y el traje de paisano, que me dieron once, y un pergamino con marco dorado que ponía: «A nuestro fiero capitán, la Compañía agradecida», que me dieron catorce pesetas. ${ }^{8}$

Por su parte, la burguesía urbana parece no pasar por ningún tipo de estrechez económica. Su afán por entroncar con la nobleza para consolidar su prestigio social les lleva a imitar los usos y costumbres del fascinante mundo nobiliario, llegando a derrochar grandes sumas de dinero en lujos que están al alcance de muy pocos. Éste es el caso de la familia de don Carlos en La corbata, que, independientemente de quién sea el prometido de su hija Marileo, celebrará el banquete nupcial en el Hotel Ritz, después de una multitudinaria y suntuosa ceremonia en la iglesia de la Concepción o en los Jerónimos:

Eugenia.- [...] Sea con quien sea, se casa en los Jerónimos o en la Concepción. Y daremos el lunch en el Ritz. [...] Tendremos por lo menos quinientos invitados. Hay que procurar que los apadrinen los Condes de Ruidera. Se va a llenar la casa de regalos. No sé si daré abasto con mi Seat 600 para tanta compra. Me tendréis que dejar un coche grande [...] Si pudiéramos lograr que fueran Paquita Rico y Lola Flores a bailar. ¡Sería magnífico! ${ }^{9}$

A pesar de esta primera diferencia, podemos señalar que, a priori, ambos grupos sociales hacen gala de una concepción moral muy similar. En las comedias de Alfonso Paso, tanto la clase media-baja como la burguesía urbana se muestran portadoras de un mismo código moral, basado en la defensa de los valores más tradicionales y conservadores. Este hecho resulta especialmente paradójico en el caso de la burguesía urbana, para la que quizás podría suponerse una mayor relajación de costumbres. Sin embargo, para este grupo social este aparente conservadurismo moral e ideológico se convierte en un simple juego de apariencias, ya que, como señala Ilárraz Eslava, «conserva la tradición pero a sabiendas de que es una mera máscara» que «uno no se la puede quitar impune o

8. Paso, Alfonso, Los pobrecitos, Madrid, Escélicer, 1962, p. 36.

9. Paso, Alfonso, La corbata..., pp. 10-13. 
descaradamente $»^{10}$. A pesar de esto, Paso opta por desenmascarar y mostrar a la élite burguesa como un ejemplo de sociedad a evitar, llena de hipocresía, vicios e inmoralidades ocultas y reprobables. Así sucede, por ejemplo, en Tan alegre, tan extraño. En esta comedia, estrenada el 23 de agosto de 1966 en el Teatro Colón de La Coruña, Paso carga «contra los procedimientos habituales de esa sociedad, contra la mentira del uso social $»^{11}$, prácticas que se concentran en los personajes de Margarita y Antonio:

Margarita.- Hija, me importa un comino lo decente en abstracto. Me interesa lo decente respecto a los demás y respecto a los demás puedo asegurarle que lo decente es que nadie se entere de nada. ${ }^{12}$

AnTonio.- [...] Has abandonado una carrera brillante, has dicho no a una fortuna y a una posición, le has sacado la lengua a todo lo que nosotros estimamos como más fundamental e importante. ${ }^{13}$

Como podemos comprobar, Paso ejerce de tenaz defensor de la sufrida clase media, que, en su lucha eterna, se nos presenta como la única clase social verdadera y auténtica, siempre «en una constante situación de inferioridad, sin ninguna posibilidad de rebeldía y portadora de una serie de prejuicios sociales tradicionales de los que ni quiere ni puede abdicar, ya que constituyen la razón y el ser de su existencia» ${ }^{14}$.

Dejando a un lado la falsedad moral que caracteriza a la burguesía urbana en las obras de Alfonso Paso, podemos decir que, en líneas generales, la clase media de las comedias del dramaturgo madrileño se caracteriza por una apatía y un conformismo generalizado con respecto a todos y cada uno de los aspectos que rodean a sus vidas, lo que hace que éstas sean aburridas y monótonas, «sin grandes problemas, ni grandes tragedias» ${ }^{15}$. Cuando estos personajes interaccionan con otros verdaderamente intrépidos e inconformistas ${ }^{16}$, sienten que éstos

10. IlárRaz Eslava, Félix Guillermo, «La sufrida y alegre clase media...», p. 126.

11. Paso, Alfonso, Tan alegre, tan extraño, Madrid, Escélicer, 1967, p. 5.

12. Ibidem, p. 71.

13. Ibidem, p. 48.

14. Mathias, Julio, Alfonso Paso..., p. 86.

15. Paso, Alfonso, Veraneando, Madrid, Escélicer, 1964, p. 87.

16. Como a continuación veremos, este tipo de personajes aparece representado en la mayoría de las comedias de Alfonso Paso por los jóvenes. Este colectivo, lejos de aceptar los preceptos y normas por los que rige la vida de los más mayores, tratará de llevar a la práctica una forma de vida alternativa, basada en una mayor libertad y en una ruptura con todos los cánones sociales del momento. Esta circunstancia, común en la vida cotidiana de finales del franquismo, hará que nuestro dramaturgo incluya en algunas de sus comedias - iEstos chicos de ahora!, Papá se enfada por todo, Tan alegre, tan extraño o Cosas de papá y mamá- los choques generacionales como tema principal de las mismas. 
«están cargándose una manera de vivir y un concepto de la vida» ${ }^{17}$ y llegan a la conclusión de que «alguien vive de otro modo y que él se aburre como una ostra. Pero no le queda otra solución que aburrirse así toda la vida $»^{18}$. Esta apatía se plasma especialmente en dos de las cuestiones más espinosas y peliagudas del contexto sociocultural de la época: la política y la religión. Ambos temas rara vez son materia de discusión seria, y Paso, muy hábilmente, hace que sus personajes pasen de puntillas sobre ellos. Los más humildes no tienen tiempo para detenerse en estos temas, quizás porque, dadas las circunstancias sociales en las que se encuentran, los consideran temas accesorios y banales; y los más pudientes se muestran abúlicos y apáticos ante la difícil y espinosa situación política y religiosa del momento, que, dada su posición social, en poco o nada les afecta.

A pesar de esto, un reducido número de personajes de esta clase media muestra una actitud inconformista y un verdadero germen revolucionario, que, lejos de lo que podríamos pensar, no tiene su origen en los ideales extranjeros importados a través del turismo o del éxodo migratorio, sino que nace en el mismo seno de la clase media, como consecuencia de su propia evolución ideológica. Los jóvenes, intelectuales e incluso algún sector del clero, son los colectivos que muestran un mayor descontento ante los problemas sociales del momento. Los más jóvenes, como Jorge en Rebelde o Susana en Las niñas terribles, muestran cierta rebelión con respecto a las leyes o preceptos sociológicos que rigen determinados aspectos matrimoniales.

SANCHO.- ¡Mira cabezota! No puede uno amarse cuando le venga en gana y tener niños por instinto. Ya te he dicho que hay unas leyes más limpias y elevadas.

JoRGE.- Pero tener un niño siempre debe ser bonito, debe ser hermoso y magnífico. No hay que mancharlo tanto... iverdad, padre? Debe prevenirse que esta mujer ha de estar alegre con su hijo y no llenarla de vergüenza. Seguro que esa ley le da a usted cien puntapiés. ${ }^{19}$

Susana.- Vete a la porra. Voy a casarme con Sam hagas lo que hagas y digas lo que digas. [...] ¿Me crees capaz de renunciar a mi amor sólo porque tú digas que no? ${ }^{20}$

La sátira social que ejerce nuestro dramaturgo contra la alta sociedad, contra todo su mundo, lleno de prejuicios, de inquietudes sin sentido, de «leyes torpes

17. Paso, Alfonso, Cuando tú me necesites, Madrid, Escélicer, 1961, p. 62.

18. Paso, Alfonso, Veraneando..., p. 6.

19. Paso, Alfonso, Rebelde, Madrid, Escélicer, 1962, p. 38.

20. Paso, Alfonso, Las niñas terribles, Madrid, Escélicer, 1960, p. 51. 
e injustas ${ }^{21}$, hacen que los más jóvenes, portadores de un código moral en el que priman unos ideales muy distintos a los de «la sociedad instituida» ${ }^{22}$, «se apoderen de la simpatía de cuantos les conocen, y les obliguen a pensar, a creer, a reaccionar frente a los problemas de ética y de sociabilidad, como ellos piensan, creen y reaccionan $»^{23}$.

Por su parte el clero, que fue uno de los apoyos fundamentales durante los primeros veinte años de vida del régimen, comienza en este momento a mostrar cierto rechazo con respecto al sesgo excesivamente tradicionalista y a la injusticia social que rige determinados aspectos de la sociedad del momento. Por ejemplo, don Enrique, en Las buenas personas, encarna la figura del cura obrero y se muestra especialmente preocupado por el dolor y el sufrimiento de los más desfavorecidos.

EnRIQue.- (Casi furioso consigo mismo) No. Me reclaman con urgencia de otros lugares con conflictos sociales, con hambre, con sangre. Esto ahora es lo primero. (Rabioso) ¿O no? [...] ¿O cada ser humano tiene el mismo precio desde el rico, a la mujer del quinto piso a la masa de criaturas angustiadas? [...] ¿O estamos despreciando a cada criatura para ocuparnos de la colectividad y ya no existen más lágrimas que las que lloran ochenta mil personas y las de un ser humano sólo no me conciernen? ${ }^{24}$

Paso muestra su simpatía con este tipo de personajes que, cansados de «tanta zarandaja tradicional ${ }^{25}$, tratan de romper con las rígidas estructuras eclesiásticas, basadas -al igual que las del régimen- en el respeto de la jerarquía y el orden. La rebeldía de este sector del clero que, como señala Martín de Santa, «fue denominado contestatario» ${ }^{26}$, se ha confundido con los intentos de democratización de una sociedad que, en esos momentos, se encontraba bajo el autoritarismo del régimen franquista. Sin embargo, Paso no lleva su protesta hasta estos extremos. Nuestro dramaturgo sólo busca una ruptura con la tradición en determinados aspectos, que permitan a la clase media llevar a cabo una transformación lenta, progresiva y paulatina dentro de las mismas estructuras sociales existentes, confiando en su propia vitalidad como medio para conseguir esos

21. Molero Manglano, Luis, Teatro español..., p. 124.

22. Torrente Ballester, Gonzalo, «Rebelde de Alfonso Paso», Primer Acto, 31, (1962), p. 42.

23. Molero Manglano, Luis, Teatro español..., p. 125.

24. PAso, Alfonso, Las buenas personas, Madrid, Escélicer, 1961, p. 82

25. Ilárraz Eslava, Félix Guillermo, «La sufrida y alegre clase media...», p. 132.

26. Martín de Santa Olalla Saludes, Pablo, «El clero contestatario de finales del franquismo. El caso Fabara», Hispania Sacra, vol. 58, 117 (2006), p. 224. 
cambios. Estos planteamientos distan mucho de los propuestos por Alfonso Sastre en el Manifiesto del T.A.S. (Teatro de Agitación Social), en el que defendía la necesidad de «llevar la agitación a todas las esferas de la vida española» ${ }^{27}$, y con los que Paso, aunque por un breve período de tiempo, llegó a simpatizar.

\section{La mujer en la obra de Alfonso Paso}

Para comprender y analizar correctamente el papel que juega la mujer dentro de la producción dramática de Alfonso Paso es imprescindible conocer, en su justa medida, la función que desempeña el género femenino dentro de la situación personal del propio autor, ya que, como señala Margit Raders, «existe una estrecha vinculación entre la obra y la vida de Alfonso Paso» que hace que ésta «parezca una prolongación de su obra, o sea, una continua puesta en escena de una pieza teatral, en la que a él le corresponde el papel de protagonista, rodeado de sus heroínas en papeles subordinados ${ }^{28}$. Decimos esto porque todas las mujeres que en algún momento de sus vidas mantuvieron una relación afectiva con Alfonso Paso se mostraron sumisas a los intereses y deseos de éste, que supo aprovechar esta relación de dependencia para potenciar su masculinidad y realzar su imagen pública cara a los demás.

Teniendo en cuenta esta distribución de papeles, podemos comentar que en la mayoría de obras que componen el corpus dramático narrativo y fílmico de Alfonso Paso la mujer aparece representada bajo ese prisma de inferioridad, servilismo y sumisión típico de una sociedad tan rígida y patriarcal como la franquista. Sin embargo, este hecho no supuso ninguna traba para Paso, que cosechó innumerables y rotundos éxitos con la mayoría de sus obras y, en especial, con aquéllas que reflejaban de una flagrante, pero a la vez amena y divertida, la difícil situación social de la mujer en época franquista. Sirvan como ejemplo dos de las obras sobre las que articularemos esta parte de nuestro estudio: Los derechos de la mujer y Enseñar a un sinvergüenza.

En estas comedias, al igual que ocurre en el grueso de la producción dramática pasoniana, nuestro autor no trata de motivar al público femenino ofreciéndole un modelo de emancipación, sino que presenta unos personajes y unos conflictos con los que busca reproducir y perpetuar la situación moral discriminatoria de la mujer durante la época franquista. Lejos de lo que podríamos pensar, este

27. SAstre, Alfonso, «Manifiesto de T.A.S.», en Teatro, Madrid, Taurus, 1964, p. 99.

28. RADERS, Margit, «La mujer en la vida y obra de Alfonso Paso: una contribución a la cultura de masas en el franquismo», en Tua Blesa et al. (eds.), Actas del IX Simposio de la Sociedad Española de Literatura General y Comparada, Zaragoza, Universidad de Zaragoza, 1994, vol. I, pp. 323-324. 
tipo de obras han pasado a ser un punto de referencia dentro de la producción dramática pasoniana y un claro ejemplo de la popularidad y éxito que cosechó nuestro dramaturgo a lo largo de su dilatada carrera profesional. Decimos esto porque la gran acogida que tuvieron estas obras entre el público y la crítica de su tiempo hizo que se llevasen a cabo diversas reposiciones a lo largo de la década de los setenta y que, al igual que sucede con otras obras de nuestro dramaturgo, se filmase una versión cinematográfica.

En Los derechos de la mujer, estrenada el 2 de marzo de 1962 en el Teatro Club de Madrid, Paso nos deja entrever, ya desde la dedicatoria de la obra, que su admiración dentro de esta pieza va dirigida exclusivamente para el género masculino, por lo que no duda en dedicársela irónicamente, dado el título de la misma, a «esa especie en trance de extinción: el hombre $»^{29}$. En esta comedia Paso nos muestra «el retrato burlesco de la eterna lucha por el mando entablada entre un hombre y una mujer $»^{30}$. Juan, joven ejecutivo, y María José, impetuosa abogada, luchan por establecer su propia jerarquía dentro de su matrimonio. Juan, «tipo extraño y divertido de sinvergüenza» ${ }^{31}$ en clara situación de inferioridad intelectual y social con respecto a su esposa, al ver que ésta no acepta tomar las responsabilidades del hogar -algo que según su concepción social le sería innato- decide hacerse cargo, para contrariarla, de los quehaceres de la casa, pasando a convertirse en «lo más mujer que se puede concebirse en un hombre $»^{32}$.

Esta inversión de las funciones que se consideraban propias del hombre y de la mujer da lugar a una serie de escenas que Paso aprovecha para burlarse irónicamente de la condición social de la mujer y ridiculizar las labores domésticas que éstas desempeñan. De esta manera, detrás de un manto humorístico y satírico, Paso trata de reflejar hasta qué aciagos extremos se puede llegar con una inversión de las funciones «naturales» de marido y mujer.

M. ${ }^{a}$ José.- ¿Pero es que...?

JuAn.- ¿Qué?

M. ${ }^{a}$ José.- ¿ ¿No vas... a darme... un beso?

JuAN.- No.

M. ${ }^{a}$ José- Pero yo espero...

Juan.- No, no. Estás equivocada. El que espera soy yo.

M. a JosÉ.- ¿Qué?

29. Paso, Alfonso, Los derechos de la mujer, Madrid, Escélicer, 1962, p. 7.

30. Ibidem, p. 5.

31. Ibidem, p. 6.

32. Ibidem, p. 43.

Pasado y Memoria. Revista de Historia Contemporánea, 8, 2009, pp. 221-243 
JuAn.- Que en el reparto de funciones... me tocó esperar. ${ }^{33}$

Finalmente, como no podía ser de otra manera, Juan logra su propósito y conseguirá que María José «deje voluntariamente de ser hombre ${ }^{34}$ reduciendo su actividad únicamente al ámbito del hogar. Una vez que el hombre inferior ha triunfado sobre la mujer más inteligente, a ésta no le queda más remedio que recuperar «su feminidad» y volver a aceptar las funciones que, por razones meramente genéticas, la intrincada y arcaica sociedad franquista le ha asignado. De esta manera Paso trata de ensalzar un modelo familiar típico de la España tradicional, basado en la negación de la capacidad intelectiva de la mujer, que quedaba circunscrita exclusivamente al ámbito del hogar donde ejercía el papel de esposa y madre que gobierna la casa, atiende al marido y educa a los hijos. Dentro de esta concepción familiar, de la que nuestro dramaturgo hizo gala a lo largo de su extensa obra, al hombre, por su condición social, le correspondía el papel de obrero de la familia, que debía de procurar todo lo necesario para el sustento y desarrollo de ésta, siempre dentro de los requerimientos y exigencias de su clase social.

Muy similar en su estructura, planteamiento y personajes es una de las obras con las que Paso cosechó uno de los mayores y más rotundos éxitos del teatro español de posguerra: Enseñar a un sinvergüenza $a^{35}$, estrenada el 15 de noviembre de 1967 en el Teatro Victoria de Barcelona. En una trama perfectamente previsible, Paso nos muestra una variante sobre el mismo tema de Los derechos de la mujer. Rosana, una joven licenciada que «no tolera el mandato y la imposición de un hombre $\aleph^{36}$, recibe el encargo de dar clases de cultura general y francés a Lorenzo, un perfecto sinvergüenza y caradura que vive del juego y se dedica al ocio. En su afán por tratar de que éste muerda el polvo y hacer de él un ser civilizado y normal, Rosana, prototipo grotesco de mujer sabihonda e independiente, aparece caracterizada con una serie de rasgos escénicos de lo más ridículo, que poco o nada tiene que ver con los que definirán a la adorable, dulce y sumisa Rosana que aparece al final de la obra, cuando Lorenzo ya ha logrado hacer «una mujer de ese ser intolerable» ${ }^{37}$.

33. Ibidem, p. 41.

34. Ibidem, p. 43.

35. Esta comedia se convirtió en un fenómeno social en la época de su estreno, convirtiéndose en la más taquillera y representada en las últimas décadas del pasado siglo con más de 14.000 representaciones y diez millones de espectadores en los 17 años que la obra se mantuvo en cartel. Acusada por la extrema derecha de fomentar la promiscuidad, la burla a la Iglesia, el lenguaje soez y la revolución sexual, pasó a convertirse en todo un taquillazo y catapultó a la fama a, por el entonces desconocido, Pepe Rubio.

36. PAso, Alfonso, Enseñar a un sinvergüenza, Madrid, Escélicer, 1968, p. 14.

37. Ibidem, p. 40. 
Rosana.- Al haberse retrasado veinte minutos se retrasa todo el ritmo de la casa exactamente veinte minutos. La cena se retrasa veinte minutos, yo tardo veinte minutos más en acostarme $y$, por lo tanto, son veinte minutos que robo al sueño o al estudio. [...] Con vuestro estúpido retraso habéis motivado una pequeña catástrofe dentro de la vida hogareña. ${ }^{38}$

Rosana.- ¡No, por Dios! ¡No te vayas! ¡Si te vas, me mato! Soy bonita, mírame. Mira mi pelo, y mis ojos. Y cuando quiero le doy a la colorá con mucha gracia. Yo no te pido más que me dejes seguirte. Yo paso por tu aro, pero si tú te vas, me mato. ${ }^{39}$

Esta función pedagógica del hombre sobre la mujer se hace mucho más patente en la obra Educando a una idiota, estrenada el 17 de septiembre de 1965 en el Teatro Carlos Arniches de Madrid. En esta comedia Carlos hace de profesor de una joven y prometedora actriz, Lola Vargas, que, a pesar de su fama y popularidad, carece de la cultura y modales necesarios para protagonizar determinados papeles. Al conocer a Lola nuestro particular Pigmalión decide terminar su relación con Isabel, su culta e inteligente novia, a la que Paso caracteriza con el burdo y repetitivo arsenal de tópicos que ya hemos descrito.

Carlos.- Que eres un petardo. Que no hay quien te aguante. Que tu padre ha tenido desprendimiento de retina por no verte. [...] Que tienes por piernas dos alambres y eres una finolis que para suspender a los alumnos les dices «Suspenzo». Con zeta, porque hace fino enseñar los dientes [...] que un hombre y una mujer no se van a pasar la vida hablando de Aristóteles por muy universitarios que sean. Hay otras cosas en que ocuparse para las que no sirves en absoluto. A- porque eres fría, te las das de superior y en el fondo piensas que demostrar las emociones es de muy mala educación. B- porque tienes una salud de esa moderna, o sea, ruinosa. C- porque en la vecindad te llaman «La gallina matada a escobazos». ${ }^{40}$

Como podemos comprobar, en las comedias de Alfonso Paso el hombre es siempre el que cambia a la protagonista femenina, ya sea librándola de su mala vida o redimiéndola de su intelectualismo desfeminizador. De esta manera, nuestro dramaturgo hace que sus protagonistas acaben tan escarmentadas de sus sueños y utopías emancipadoras -circunstancias que únicamente podían llevarlas a

38. Ibidem, p. 12.

39. Ibidem, p. 85.

40. PAso, Alfonso, Educando a una idiota, Madrid, Escélicer, 1964, p. 73. 
la perdición o a un efímero triunfo profesional que desembocaría en un fracaso en las verdaderas funciones de la mujer, las de esposa y madre- que terminan rendidas y sumisas a los deseos y órdenes de sus maridos, a los que terminan considerando como seres superiores de los que aspiran a ser su apoyo y auxilio. Así sucede, por ejemplo, en La fiebre de Junio donde Aurelia, a pesar de autoproclamarse «el progreso $»^{41}$ por sus denodados intentos de convertirse en una mujer independiente en la que «jamás un hombre pueda mandar $»^{42}$, acabará sometida a la voluntad de Juan, un perfecto vago que dará al traste con sus esperanzas de poner un despacho y tener la posibilidad de ejercer la carrera de Derecho.

Aurelia.- Espera. (Está turbada, confusa) Soy una mujer normal. Me casaré y tendré hijos. [...] Juan, por piedad. Haré lo que tú quieras, te seguiré descalza como una gitana. Tú mandarás. Seré una esclava, una asquerosa esclava, una repugnante esclava. Pero te necesito. Te quiero, ¿lo oyes maldito? Te quise desde que me dijiste la primera grosería. ¡Te quiero! ¡Te quiero! Y lo voy a gritar para que se entere todo el barrio. ¡Te quiero! ${ }^{43}$

Así pues, y como hemos podido comprobar a lo largo de este apartado, la mujer en las comedias de Alfonso Paso siempre queda representada desde una perspectiva masculina, valiéndose de unos clichés muy marcados y definidos que nuestro dramaturgo utilizó repetitiva y machaconamente cada vez que sus peripecias argumentales le daban ocasión. De esta manera Paso trata de justificar «el papel tradicional de la mujer dentro de la familia y del hogar ${ }^{44}$ impuesto por la ideología oficial, haciendo que sus obras escenifiquen los postulados de la educación franquista para el género femenino, que se cimentaban en una ineludible sumisión al hombre, en la conservación de la decencia y la honra dentro del matrimonio y en la procreación como una función innata a su existencia.

\section{Los cambios y transformaciones de la sociedad española en las comedias de Alfonso Paso}

Si comparamos la sociedad española del inicio del franquismo con la de mediados de la década de los sesenta, podemos comprobar que entre ambas media una distancia muy significativa, fruto de unos importantes y profundos cambios.

41. Paso, Alfonso, La fiebre de Junio, Madrid, Escélicer, 1965, p. 32.

42. Ibidem, p. 46.

43. Ibidem, pp. 87-88.

44. Ortiz Heras, Manuel, «Mujer y dictadura franquista», Aposta. Revista de Ciencias Sociales, 28 (2006). 
Éstos, que en su mayoría tienen su origen en las nuevas medidas económicas adoptadas a raíz de la implantación del primer Plan de Estabilización, modificaron sustancialmente las características propias de una sociedad tradicional como la española, en la que hasta ese momento habían predominado las formas culturales y pautas de comportamiento de tradición rural. En poco más de una década la modernización de la sociedad española se hizo más que evidente, pasando a adoptar un modelo de conducta basado en una mentalidad más abierta y tolerante, en la que comenzaban a primar determinados conceptos, hasta entonces desconocidos, como el consumismo o una mayor laicidad.

Estas circunstancias, que suponen un punto determinante en la configuración de la sociedad española actual, no pasaron inadvertidas para nuestro dramaturgo, que supo plasmar con la misma vitalidad y frescura de siempre parte de la compleja realidad de una sociedad que se hallaba inmersa en pleno proceso de cambio. Decimos esto porque, como a continuación tendremos ocasión de comprobar, Paso refleja la compleja transformación de la sociedad española basándose únicamente en aspectos muy parciales de la realidad del momento -innovaciones tecnológicas, turismo, consumo- con los que trataba de promocionar la imagen y la aparente modernidad del régimen franquista. De esta manera el dramaturgo madrileño hizo caso omiso a las voces de protesta de parte de la crítica teatral del momento que, con Ricardo Domenech a la cabeza, le sugerían abordar «de una manera viva, directa, sin escamotearse en ningún momento la dimensión trágica de la realidad española» ${ }^{45}$. A pesar de esto, Paso optó por poner en escena un sinfín de obras con poca o ninguna intención crítica, que, lejos de las primeras tragicomedias en «donde las características de la colectividad española eran examinadas de bien distinto modo» ${ }^{46}$, únicamente reflejaban los aspectos más avanzados de la burguesía urbana y de la creciente clase media.

De esta manera nuestro dramaturgo se sirvió, por ejemplo, de la mejora generalizada de la economía española y de la posterior incorporación de una parte importante de los españoles a una sociedad con claros matices consumistas para articular parte de su ingente obra. La recién nacida veta consumista afectó a todos los estratos sociales de la dramaturgia pasoniana, aunque es en los colectivos económica y socialmente más desfavorecidos donde este fenómeno tiene más relevancia. Por una parte tenemos a la clase media que, en su afán por imitar los usos y costumbres del fascinante mundo nobiliario, opta por utilizar las nuevas formas de compra surgidas a raíz de la implantación de los patrones consumistas

45. Domenech, Ricardo, «Prefiero España de Alfonso Paso», Primer Acto, 58 (1964), p. 66

46. Monleón, José, «Las que tienen que servir de Alfonso Paso», Primer Acto, 36 (1962), p. 40.

Pasado y Memoria. Revista de Historia Contemporánea, 8, 2009, pp. 221-243 
en la sociedad española. Así pues, cuando tratan de adquirir un electrodoméstico o cualquier otro bien que, dada su naturaleza, los haga entroncar con las élites sociales, los actuantes pasonianos hacen uso de la modalidad de pago aplazado. Esta forma de liquidación, muy frecuente en la España de la década de los sesenta, permite a nuestros personajes acceder a determinados bienes que, de no ser por esa forma de pago, les resultaban prácticamente inalcanzables por su elevado coste. Sin embargo, el pago aplazado también entrañaba sus problemas ya que a la larga el grueso de la economía familiar quedaba totalmente hipotecado provocando que el nivel de endeudamiento aumentase considerablemente y fuese cada vez más difícil llegar a final de mes.

MeRCEDES.- [...] ¡Antonio! La letra del traje.

Antonio.- Págala.

MERCEDES.- Es que ha venido la letra de la nevera y he tenido que pagarla.

Antonio.- ¡Vaya! Pues coge el dinero de la letra del abrigo de la niña y ya lo repondremos.

MeRCEDES.- Con el dinero de la letra del abrigo de la niña he pagado la letra de la cristalería y me queda de cola la letra de la silla de ruedas de mamá. [...]

Antonio.- (Para sí.) Claro. Si no puede ser. Si no gano más que tres mil ochocientas pesetas y he firmado letras por valor de doscientas mil. Si tiene que pasar algo muy gordo. ${ }^{47}$

Por su parte, los colectivos más desfavorecidos, social y económicamente hablando, se sirvieron de la amplia gama de productos derivados del desarrollismo de la década de los sesenta para enmascarar, en la medida de sus posibilidades, su delicada situación socioeconómica. Sin embargo el encubrimiento de su verdadera posición social escondía -según palabras de nuestro dramaturgo- unas «tragicómicas ansias de prosperar» ${ }^{48}$. Así sucede por ejemplo en La boda de la chica, una divertida comedia en la que Paso pone en escena los denodados esfuerzos de Fernanda por impresionar al novio de su hija Antonia, un joven ingeniero con el que espera redimirse de su posición social y solventar sus problemas económicos. Para lograr esto hace que toda la familia se vuelque en conseguir el dinero suficiente para comprar productos de lujo con los que agasajar a su invitado, aunque para ello tengan que empeñar lo poco que tienen.

47. Paso, Alfonso, La corbata..., pp. 30-31.

48. PAso, Alfonso, «Algo más que una obra bien hecha», Primer Acto, 14 (1960), p. 17. 
Fernanda.- [...] Baja a la mercería y deja las sábanas y la colcha a Don Damián. Te darán quince duros. Compra champán. [...]

JoAQuín.- ¿Cuántas botellas?

FERnANDA.- Lo que den de sí los quince duros. ¡Va a ser un taponazo sonado! [...] Baja a los ultramarinos. [...] Compras chorizo de cantimpalo, almendras, avellanas, galletas. ${ }^{49}$

Este fragor consumista, además de poner de manifiesto las ansias de ascenso social de una parte de la población -clase media y clase baja-, sirve para que Paso enjuicie a la burguesía urbana por su frivolidad, ya que su vida se mueve únicamente para ampliar su patrimonio personal. De la misma manera, nuestro dramaturgo tampoco considera lícitas las prácticas consumistas de la clase baja, a la que acabará juzgando por su falsedad e hipocresía, dado que trata de llevar una vida basada en las apariencias y en estar siempre por encima de sus verdaderas posibilidades económicas. Frente a esto, Paso trata de ensalzar la honradez y el pundonor de la clase media, de su querido público, que, a pesar de estar «condenados a ser pobres» ${ }^{50} \mathrm{y}$ de contar con unos ingresos muy reducidos, conseguirán, gracias a su esfuerzo, trabajo y sacrificio, tener acceso a la mayoría de bienes que caracterizan a la moderna sociedad de consumo.

Dejando a un lado el reflejo literario de la llegada de los hábitos consumistas a la sociedad española de la década de los sesenta, también queremos destacar otro de los aspectos sociales más relevantes de la España del momento: los choques generacionales. Éstos tienen su origen en el distanciamiento tan significativo que existe entre los jóvenes de las comedias de Alfonso Paso y la generación anterior a la Guerra Civil, o lo que es lo mismo, entre hijos y padres. Nuestro dramaturgo fundamenta este alejamiento en la diferencia que existe entre el modelo de sociedad en el que crecieron y maduraron los padres y en el que han crecido y se están insertando como adultos los hijos. La imagen que los más jóvenes tienen de la España que vivieron sus padres es la de un país marcado políticamente por la dictadura y la represión, y económicamente por la precariedad y el aislamiento. Esta imagen contrasta con la realidad que ellos han vivido, ya que son la primera generación de jóvenes que ha crecido inmersa en la cultura del consumo y tiene cierta facilidad para poder acceder a los estudios universitarios. De esta manera no es de extrañar que los hijos no se consideren ni herederos ni continuadores del austero estilo de vida de sus padres, por lo que llegan a referirse a él como «otro mundo ${ }^{51}$ o incluso como «otro tiempo» ${ }^{52}$.

49. PAso, Alfonso, La boda de la chica, Madrid, Escélicer, 1961, p. 40.

50. PAso, Alfonso, La corbata..., p. 90.

51. PAso, Alfonso, Tan alegre, tan extraño..., p. 68.

52. Paso, Alfonso, ¡Estos chicos de ahora!, Madrid, Escélicer, 1968, p. 51. 
Con la puesta en escena de esta confrontación de ambos sistemas culturales Paso trata de poner de manifiesto una de las consecuencias más directas de los choques generacionales: la incomunicación entre padres e hijos. Esta circunstancia hace que los padres dejen de ser un marco de referencia para sus congéneres y que otros jóvenes, con ideales y formas de vida muy dispares a las suyas, ocupen el vacío dejado por ellos. De esta manera, nuestro dramaturgo hace que sus obras sean un fiel reflejo del importante proceso de transformación en el que quedaron inmersas las relaciones familiares de la España de los sesenta, no sólo en lo que atañe a los vínculos de unión entre padres e hijos, sino también en lo referente a las formas de convivencia en pareja. Así pues, Paso pone en escena, aunque de manera muy atenuada, las diferencias entre el arcaico modelo familiar de los progenitores, basado en la defensa de los valores tradicionales y en un sometimiento total a la autoridad paterna, y otro, mucho más heterogéneo, en el que las formas de familia no se rigen exclusivamente por lo que dicta la tradición. Esta circunstancia, incomprensible según la mentalidad de los padres, lleva a muchos de ellos, como es el caso de Juan en iEstos chicos de ahora!, a renegar de las nuevas costumbres y del modo de vida impuesto por sus hijos.

JuAN.- [...] Admito sólo una cosa: que estos chicos de ahora son unos inmorales, que no tienen decencia, que no saben con qué se comen la honestidad y el respeto, que no conceden valor a nada, que no les gusta trabajar [...] y que son una partida de sinvergüenzas como no he visto jamás nada igual [...] pero no acepto ese mundo ni lo aceptaré [...] hay una ley, unos cauces. En mis tiempos sucedían las cosas de otra manera. ${ }^{53}$

Sin ninguna duda, Paso no sólo trataba de poner de manifiesto a través de este tipo de choques generacionales el proceso de cambio en el que se hallaba inmersa la sociedad española, sino también la superioridad, tanto en el terreno cultural como en el social, del modo de vida impuesto por la juventud y con el que él se sentía claramente identificado. De este modo, nuestro dramaturgo conseguía un doble propósito. Por una parte, lograba poner en escena un tema de la más rabiosa actualidad y, por otra, trataba de demostrar su aparente modernidad tanto en el terreno ideológico como en el cultural.

53. Ibidem, pp. 51-52.

Pasado y Memoria. Revista de Historia Contemporánea, 8, 2009, pp. 221-243 


\section{El influjo del turismo y la emigración en la España de los años 60: su reflejo en la obra de Alfonso Paso}

Como ya hemos comentado, la sociedad es el ámbito en el que se produjeron más cambios y de mayor calado en la España de la década de los sesenta. Estos cambios modificaron profundamente la estructura social, transformaron sus valores y prácticas y acabaron generando un sistema en el que continuismo y renovación se fundieron en un solo conjunto, que asumió la herencia de la España tradicional y al que se acabaron incorporando muchas de las novedades del mundo moderno. De entre las numerosas influencias que sirvieron para configurar el nuevo modelo cultural, queremos destacar la importancia del turismo y de la emigración, dos fenómenos sin los que nos sería imposible comprender la compleja realidad sociocultural de la España de los sesenta. Ambos contribuyeron a modernizar las costumbres y la mentalidad de la población española, ya que los hábitos que evidenciaban tanto los turistas extranjeros como la población de los países receptores de emigrantes españoles -Alemania, Francia, Suiza- diferían sensiblemente de la esencia moral española y de la doctrina nacional-católica que habían caracterizado a nuestro país hasta ese momento. De este modo surge un importante choque cultural entre las costumbres de unos y las tradiciones de otros, que sirve para que nuestro dramaturgo ponga en escena, de una manera «efectista, exagerada y caricaturesca $»^{54}$, la supremacía de los valores patrios, valiéndose para ello de los «innumerables tópicos sobre la condición del español» ${ }^{55}$ y sobre las costumbres de los extranjeros.

Así sucede, por ejemplo, en Las que tienen que servir, una obra que refleja la nueva situación de convivencia y confrontación cultural derivada de la polémica construcción de las bases militares estadounidenses en la localidad madrileña de Torrejón de Ardoz. Sin embargo, y lejos de optar por poner en escena los graves problemas políticos y morales que planteaba para la sociedad española la presencia de un mundo tan antagónico como el americano, Paso hace de esta obra un juego cómico en el que «unos cuantos gamberros y unas cuantas criadas ladronas ${ }^{56}$ nos descubrirán lo superlativo de los valores patrios.

Hasta que ese momento llega, nuestras dos heroínas, Juana y Francisca, se dejan seducir por dos simpáticos y apuestos americanos, Nathan y Spencer, que, lejos de servirse de su atractivo personal, emplean todo el prestigio y reputación

54. Marquerie, Alfredo, «Estreno de Prefiero España, de Paso, en el Cómico». No dispongo de la referencia completa de este artículo al haber sido cedido con estos datos desde el archivo particular de la familia Paso.

55. Domenech, Ricardo, «Prefiero España...», p. 66.

56. Monleón, José, «Las que tienen que servir...», p. 40. 
de la democracia norteamericana para conquistar a las crédulas e inocentes muchachas.

SPencer.- Me gustaría enseñarle muchas cosas, Francisca Pizarro. Usted puede y debe ser una criatura libre, sin ataduras. (Las que tienen que servir, 1963, p. 33).

Aunque en un principio las dos criadas dudan y desconfían de las buenas intenciones de los americanos ${ }^{57}$, el hecho de que éstos les hablen de un país diametralmente opuesto a España, en el que el hombre «cuidaría de los niños y lavaría los platos $\aleph^{58}$ y la mujer ocuparía las altas esferas de las empresas más importantes de Norteamérica, pone ante sus ojos una solución más que factible para sus grises y monótonas vidas. Juana, ensimismada por la nueva realidad que se le presenta, trata de llevar a la práctica estas nuevas costumbres con su novio Antonio, un joven castizo y achulapado que le hace ver cuál es el verdadero papel que juegan hombres y mujeres dentro de la sociedad española.

JuAna.- Y piensa bien que al terminar de cenar te pones un delantal.

Antonio.- (Levantándose) Mira, Juana, no soy tu marido, pero te voy a pegar una bofetada. [...] No sé quién te ha metido esas ideas en la cabeza. Pero sabes de sobra que no voy a fregar los platos nunca, pase lo que pase y aunque esté lleno de cadenas. [...] Yo puedo ser un sinvergüenza, un cara, un vago, lo que tú quieras, pero tú tienes que ser una santa y estar metida en casa. $O$ te pego tres tiros. ${ }^{59}$

En torno a esta oposición cultural Paso articula una demagógica disputa en la que americanos y españoles dirimen, bajo los sones del pasodoble Los voluntarios $^{60}$, cuál de las dos sociedades es la más avanzada. Mientras que los norteamericanos relatan todo su arsenal de avances tecnológicos, científicos, culturales y

57. Sirva como ejemplo este ilustrador parlamento de JuANA: «Nos birlaron las colonias. Y cuando poníamos una firma en un tratado se nos quedaban con lo bueno y nos dejaban a nosotros los Monegros con moros. En cuanto alguien viene a sacar fotografías retratan la entrada de la carretera de Andalucía con dos pobres y no retratan el Edificio España». (Paso, Alfonso, Las que tienen que servir..., p. 34).

58. Paso, Alfonso, Las que tienen que servir..., p. 36.

59. Ibidem, p. 51 .

60. Los orígenes de esta composición musical se sitúan en 1893, fecha en que Jerónimo Jiménez estrenó la zarzuela a la que pertenece. El hecho de que aparezca esta pieza musical en un momento tan crucial de la representación no es algo casual, ya que desde sus orígenes, y dado que la zarzuela de Jiménez trata la historia de unos voluntarios catalanes que van a la guerra de África, su significado siempre estuvo indisolublemente ligado a la exaltación 
políticos, los españoles se muestran orgullosos del teatro de Benavente, del jamón serrano y del aceite de oliva o tener dos equipos de fútbol punteros. Por si esto no fuera suficiente, para terminar de poner de manifiesto la «superioridad» de la cultura española, nuestro dramaturgo hace que Lorenzo, un simpático huevero que ronda a Francisca, reniegue de la forma de vivir de los americanos y que muestre a los presentes lo incomprensible y desacertada que resulta su mentalidad.

LoRenzo.- [...] No les aguantamos. No podemos soportar esa forma de vivir. ¿Qué mentalidad es la que tenemos que cambiar? Se nos han llevado la siesta y nos han dejado el Ecuanil. Cogen las teas más inaguantables que he visto. Por cualquier cosa se suicidan. Corren como galgos para al final ponerse un delantal y fregar los platos. No nos gusta, ea. No puedo aguantar tanto celofán y tanta lata de conserva, tanto coche con delirio de grandeza, tanto vaso desinfectado, tanta higiene y tanta pastilla para dormir y tanto dólar. (Frenético) A cambiar, hermano. Aprenda de mí. A dolarazos no, hombre, a dolarazos, no. (Los españoles aplauden) ${ }^{61}$

El final de la obra vuelve a redundar en esta idea. Paso nos muestra lo peligroso que puede resultar dejarse embaucar por la democracia americana y, en extensión, por cualquier otro sistema político basado en la plena libertad del individuo, ya que es en ésta donde reside «el origen de la indecencia ${ }^{62}$. Decimos esto porque el último acto de la pieza se convierte en una bofetada moral para Juana. Sus ansias de convertirse en una mujer libre y de buscar nuevos horizontes en Norteamérica casi le acarrean una paliza y una violación a manos de Nathan. La incauta muchacha, consciente del error que ha cometido, vuelve al lado de Antonio, quien le exigirá llevar una vida acorde a los verdaderos principios, valores e ideales que rigen en la sociedad española y de los que Francisca, a juzgar por el final de la obra, nunca debió renegar.

De esta manera nuestro dramaturgo no sólo consigue que esta obra se convierta en un interesado «elogio a la servidumbre», ${ }^{63}$ sino que también sea una penosa apología de los valores patrios, ya que consigue, con una puesta en escena muy del gusto del público, demostrar la superioridad de la cultura española y eludir lo verdaderamente conflictivo e inquietante de la presencia americana en España.

de los valores patrios. El régimen franquista así lo entendió y no dudó en incluir los sones de este conocido y popular pasodoble en los desfiles de victoria o en el NO-DO.

61. Paso, Alfonso, Las que tienen que servir..., p. 36.

62. Paso, Alfonso, Las que tienen que servir..., p. 41.

63. Monleón, José, Treinta años de teatro de la derecha, Barcelona, Tusquets, 1971, p. 110. 
Mucho más interesante, dada la problemática social que planteaba para la sociedad española de la década de los sesenta la emigración de trabajadores a los países de Centroeuropa, puede resultarnos Prefiero España, una obra en la que Paso retrata «las peripecias que sufren tres obreros españoles en Alemania» ${ }^{64}$. En esta comedia nuestro dramaturgo se sirve del espectacular desarrollo que tuvieron los movimientos migratorios para articular una pieza cuya única finalidad era la de hacer «reír y sonreír ${ }^{65}$ a un público que se sintió mayoritariamente atraído por el estilo "patriotero» ${ }^{66}$ de esta obra. Sin embargo, el tratamiento «efectista, exagerado y caricaturesco $»^{67}$ que da Paso a tan manido tema está muy por debajo de las verdaderas posibilidades literarias que éste ofrece, y al que autores como Lauro Olmo o Ángel María de Lera sí supieron sacar partido en obras como La camisa o Hemos perdido el sol ${ }^{68}$, en las que reflejaron la dimensión trágica de este problema en toda su extensión e hicieron que el público tomase conciencia del mismo.

Dejando a un lado esta circunstancia, podemos comentar que Prefiero España se erige en una comedia donde se cantan las excelencias hispanas frente al oscurantismo de la cultura foránea, en este caso de la sociedad alemana. En una trama perfectamente previsible, Paso nos muestra la azarosa vida de Felipe, Chumi y Antón, tres obreros españoles que, atraídos por las mejores condiciones laborales y por las posibilidades de progreso $0^{69}$ de la sociedad bávara, se verán «obligados», dado el elevado índice de desempleo de nuestro país, a emprender su particular aventura alemana.

AnTón.- Si me quisiera se daría cuenta de que esto es una tumba y que en Alemania un obrero es un señor. [...] ¿Y no le va a dar alegría cuando vuelva forrado de billetes? Que voy a llegar al Sepu y voy a decir: «A ver para mi

64. Domenech, Ricardo, «Prefiero España...», p. 66.

65. Ibidem, p. 66.

66. Marqueríe, Alfredo, «Estreno de Prefiero España...».

67. Ibidem.

68. Ambas obras, además de describir el imparable éxodo de emigrantes españoles al resto de países europeos tras el enfrentamiento civil, muestran, con unos personajes llenos de vida y humanidad, los rasgos más sobresalientes de la cultura alemana y del carácter y mentalidad de sus habitantes.

69. A lo largo de toda la obra Paso aludirá a los innumerables tópicos que durante años pesaron sobre los movimientos migratorios. De esta manera nuestro dramaturgo consigue que Prefiero España refleje fielmente determinados anhelos de la emigración española a los países del centro de Europa, como el ansia de progreso tanto social como económico en el país receptor, el hipotético regreso al país de origen, la posibilidad de montar un pequeño negocio en España con el dinero ganado en el extranjero o el vuelco de las relaciones con el catolicismo. 
padre todo ese mostrador.» [...] Estoy contento. Voy a progresar. A labrarme un porvenir. Estoy contentísimo. (Y está llorando el muy tonto) Esto es una tumba, un asco, un desierto. ${ }^{70}$

Su estancia en una industrializada y moderna ciudad sirve para que Paso ponga en escena, valiéndose de tópicos manidos, la aparente superioridad del modelo cultural, económico y político de la sociedad alemana. De esta manera los tres obreros comprueban que «van a vivir en un país lleno de progreso, donde la moneda es fuerte y el trabajo se paga en serio $»^{71}$. Sin embargo, con el paso de los días esta situación inicial comienza a dar un giro que, conociendo los antecedentes dramáticos de Paso, resulta cuanto menos previsible. El recuerdo imborrable de España que persigue incesantemente a Antón y Chumi les hará ver «como virtudes y encantos los fallos y pecados que encontraron en España cuando vivían en ella» ${ }^{72}$. De la misma manera, cada día que pasa nuestros intrépidos personajes comienzan a percibir «los incontables defectos» ${ }^{73}$ de trabajar en la grave Alemania. La modernidad que se presuponía no existe, las posibilidades de ascenso social son prácticamente utópicas, los trabajos son duros y repetitivos y las condiciones de vida, cuanto menos, insalubres.

AnTón.- ¿Y es de justicia lo de este pabellón? ¿Dónde están los adelantos? Se los han guardado para ellos, y esto es peor que un pesebre. Mira qué camas. ¿Y las paredes? Madera de cajón llena de boquetes. Y por más que lo decimos ni nos hacen caso. Como si fuéramos negros. Negros americanos, claro. ${ }^{74}$

Una vez que nuestro dramaturgo ha puesto todas las cartas sobre la mesa sólo le queda buscar un final que reafirme todos los principios que, poco a poco y de manera casi encubierta, ha ido diseminando a lo largo de toda la obra. Así pues, Antón y Chumi, consumidos por la añoranza de España, se verán obligados a emprender el viaje de vuelta y a seguir, ya en su país, con las mismas costumbres y con los adorables vicios y defectos de los que un día renegaron. Por su parte, Felipe, opta por seguir progresando dentro de la cuadriculada y rígida sociedad alemana, aunque con el recuerdo de su querida España siempre presente. Pasajes como el que a continuación citamos dan un claro ejemplo de lo que queremos decir:

70. Paso, Alfonso, Prefiero España..., p. 18.

71. Ibidem, p. 32.

72. Molero Manglano, Luis, Teatro español..., p. 127.

73. Ibidem, p. 127.

74. Paso, Alfonso, Prefiero España..., p. 61. 
Felipe.- Lo hecho de menos. Y esto, de trágico que es, da risa. Porque no tiene solución. Porque lo llevo dentro, como el hígado y los intestinos. Y no me lo puedo quitar. Porque España no está a tres mil kilómetros. (Golpeándose el pecho) ¡Está aquí, maltita sea, aquí! ${ }^{75}$

De esta manera podemos comprobar cómo Paso hace de Prefiero España una obra «patriotera» y «lacrimógena ${ }^{76}$ en la que, como señala José Luis Sirera, «se defiende una España eterna ${ }^{77}$ donde los defectos y errores son camuflados por la semejanza que éstos tienen con respecto a los de otras naciones. Éste es, sin duda, uno de los puntos clave para entender el verdadero significado que nuestro dramaturgo quiere darle a la comedia, ya que con esta equiparación consigue demostrar que España, en comparación con respecto al resto de países europeos, no está tan atrasada como en un principio podíamos pensar y que sus problemas, a juzgar por el final de la obra, resultan poco menos que acogedores.

\section{Conclusión}

A la hora de hacer el balance de toda la producción dramática de Alfonso Paso es obligado reconocer que en torno a su extenso corpus teatral se cierne, como hemos podido comprobar, un claro anquilosamiento temático e ideológico, sobre todo en lo que se refiere a la condición social de la mujer, a la defensa de un determinado estilo de vida basado en el tradicionalismo y en el consecuente rechazo de cualquier tipo novedad sociocultural que procediese del exterior. Sin embargo, y aunque esta circunstancia, unida a la más que cuestionable calidad literaria de determinadas obras, hace que la recuperación del teatro de Alfonso Paso sea poco menos improbable no puede caer en saco roto, ya que posee una extraordinaria importancia a la hora de convertir las obras de nuestro dramaturgo en «documentos sociológicos de primer orden» ${ }^{78}$, únicamente comparables con algunas de las producciones cinematográficas nacionales de la época, que, con títulos tan sugerentes como El turismo es un gran invento (1968), Vente a Alemania Pepe (1971) o La ciudad no es para mí (1965), consiguieron, al igual que el grueso de la producción dramática pasoniana, ser fiel reflejo de una sociedad inmersa en pleno proceso de cambio.

75. Paso, Alfonso, Prefiero España..., p. 61.

76. Marquerí, Alfredo, «Estreno de Prefiero España...».

77. Sirera, José Luis, «Alfonso Paso. Esplendor y limitaciones del teatro comercial de los sesenta», en FloRECK, Wilfried y Toro, Alfonso de (coords.), Teatro español contemporáneo: autores y tendencias, Kassel, Reichenberger, 1995, p. 114.

78. Sirera, José Luis, «Alfonso Paso...», p. 120. 
De esta manera, y como hemos tenido ocasión de comprobar a lo largo de este estudio, es esta perspectiva sociológica la que dota a la obra de Alfonso Paso de un notable interés, en tanto que nos permite conocer, siempre desde un punto de vista muy tipificado y concreto, parte de la compleja realidad de la sociedad española. 